Algunas lecciones de la integración económica
en América Iratina: el caso de Centroamérica*

Hace unos veinte años, la integración económica era percibida por muchos economistas latinoamericanos como instrumento útil y promisorio para impulsar el desarrollo económico y social de sus respectivos países. La idea apelaba a los sentimientos bolivarianos -siempre latentes- y además se inspiraba, en primer término, en un marco conceptual cepalino, en boga en esa época, que asignaba gran importancia a la industrialización para impulsar el desarrollo, y que reconocía que para que esa industrialización resultase razonablemente eficiente, debería aprovechar espacios económicos y geográficos más o menos amplios. En segundo Iugar, la idea fue fortalecida por las experiencias relativamente exitosas que habían obtenido los países de Europa Occidental con su propio proceso de integración.

Hoy, gobiernos y académicos continúan rindiendo tributo retórico al potencial que entraña la cooperación entre países en vías de desarrollo en el marco de procesos formales de integración, pero parece existir un desaliento generalizado sobre el papel que esos procesos han jugado en América Latina para coadyuvar al desarrollo de los países de la región. Durante los años setenta, en efecto, se hablaba y escribía frecuentemente de la "crisis" que dichos procesos enfrentaban, y de la urgente necesidad de "reestructurarlos". En años más recientes, y no obstante la metamorfosis de ALALG a ALADI, al parecer el tema ni siquiera ha logrado concertar el interés de los estudiosos en la materia, quienes al menos en forma implícita, han dictaminado el "fracaso" de este experimento en cooperación intrarregional.

Sin embargo, el pesimismo parece ser prematuro. Si se juzga el grado de interdependencia económica que existe entre los países de la región a través del indicador clásico -el comercio recíprocoéste creció en forma significativa entre 1960 y 1975 , y desde esa fecha al presente se ha mantenido a niveles constantes.

*Este trabajo es una versión modificada y actualizada de un artículo originalmente publicado en la revista Economia de América Latina, (México, D. F., 
Como se podrá apreciar en el Cuadro 1, esta afirmación es aplicable a cada uno de los procesos subregionales de integración existentes en la región, y para la región en su conjunto. Así, en 1960, menos del $9 \%$ de las exportaciones totales de 22 países latinoamericanos se destinaban al resto de la región; ese porcentaje había subido al $16 \%$ en 1975 y se mantuvo cercano a ese nivel, con una tendencia muy moderada hacia la baja, en años posteriores. En cifras absolutas, el comercio intramegional pasó de 750 millones de dólares a 15.400 millones; o sea, en el lapso de dos décadas el valor del mismo se multiplicó por 20. El proceso que ha revelado el mayor dinamismo $-\mathrm{y}$ el mayor grado de interdependencia- ha sido el centroamericano.

Ese comercio no sólo es producto de fuerzas espontáneas o generado por proximidad geográfica. Evidentemente, la existencia de regímenes preferenciales en el marco de los tratados de integración existentes estimularon el comercio recíproco. Así, en los últimos años, aproximadamente un $90 \%$ de las exportaciones de los países miembros de ALADr al resto de América Latina se destinaron a los paises miembros de esa agrupación subregional. Igual proporción se registró en el caso del Mercado Común Centroamericano.

Es innegable que los procesos subregionales existentes también enfrentan problemas, y muchos. Asimismo, la utopía de una especie de Mercado Común Latinoamericano está aún más lejos de cumplirse que cuando los Presidentes de los países latinoamericanos se reunieron en Punta del Este en 1967 y declararon su intención de lograr ese objetivo. ¿Cómo tener un juicio más equilibrado y objetivo sobre el potencial de la cooperación intrarregional para los años ochenta y más allá, con la base en las ricas experiencias históricas? Las decisiones derivadas del funcionamiento del proceso de integración centroamericano, probablemente el más exitoso que se ha dado en América Latina, podría arrojar algunas luces sobre esta cuestión. Como se subraya en las páginas que siguen, no obstante los múltiples problemas que dicho proceso ha enfrentado a través de los años, los centroamericanos revelaron una tenaz persistencia en mantener vigente su esquema de cooperación económica intraregional.

Es útil recordar el trasfondo ante el cual los gobiernos centroamericanos decidieron darle un impulso al proceso integrador al suscribir en 1960, el Tratado General de Integración Económica. Ya se tenían aproximadamente diez años de experiencias parciales,

ler. semestre 1982, No 8) y fue presentado en la Conferencia organizada por la Third World Fundation en Cartagena, Colombia, en febrero de 1984. 


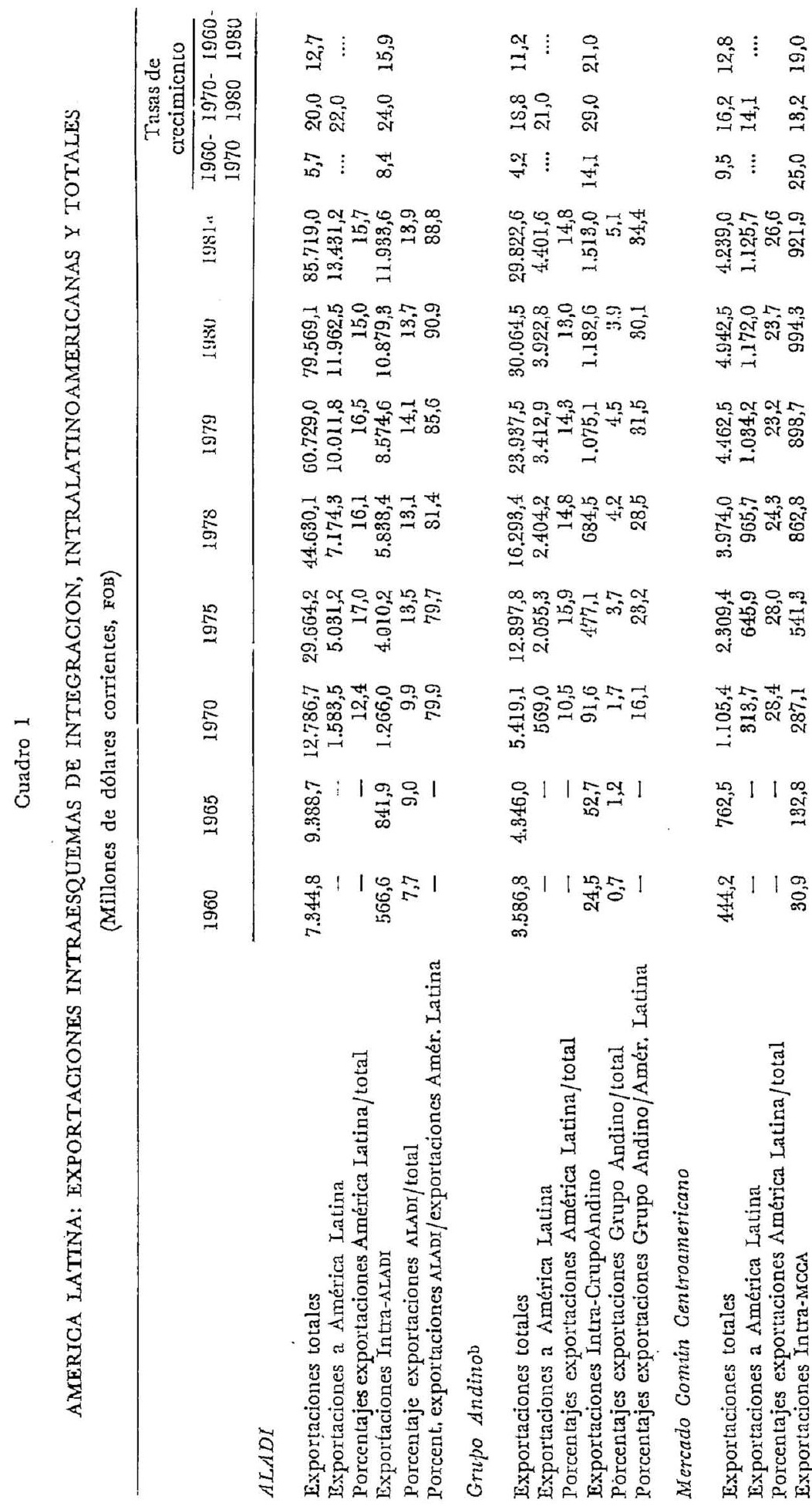




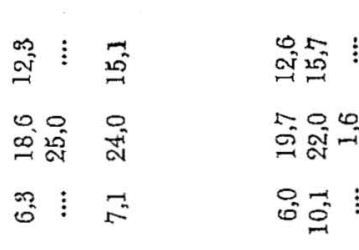

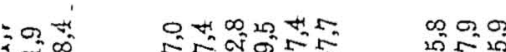

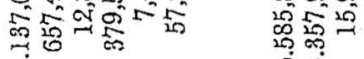

的

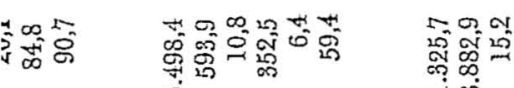

ธొ

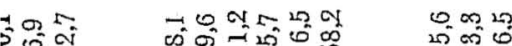
论

二

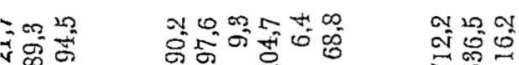
总稂 i $\infty$

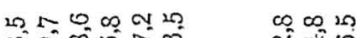

की क्ष 20

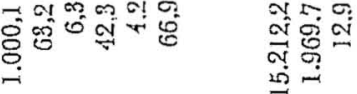

o $11-0,1 \quad 0 m=$

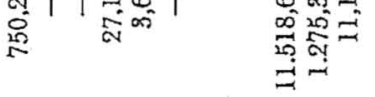

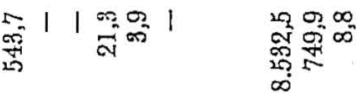

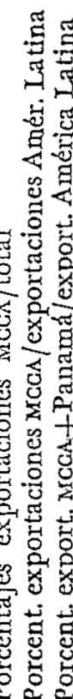

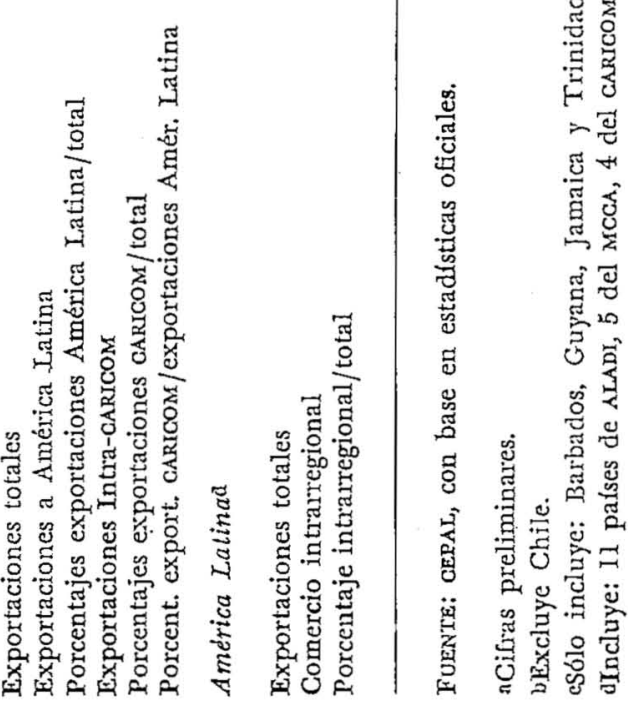


muy influenciadas en su concepción y en su ejecución por Ia Comisión Económica de las Naciones Unidas para América Latina ${ }^{1}$. En esos años, la integración en Centroamérica se concibió, fundamentalmente, como un proceso que viabilizaría la industrialización sustitutiva de importaciones en países cuyo mercado nacional no ofrecia las condiciones mínimas para permitir plantas industriales dimensionadas para aprovechar las economías de escala que las tecnologías vigentes aconsejaban ${ }^{2}$.

Como parte de ese trasfondo, cabe mencionar, en primer término, el ambiente internacional de postguerra, aún vigente en 1960, y que privilegiaba la eliminación de las barreras al comercio internacional de manera de contribuir a la prosperidad y a la interdependencia económica de todos los países de la comunidad internacional. Las grandes potencias sólo estaban dispuestas a dar su respaldo a los movimientos de integración subregional -y aún así con poco entusiasmo- que cumplían con las reglas del GATr, y particularmente con su artículo xxIv, que permitía las restricciones al comercio en el marco de una unión aduanera. Por otro lado, era un período de bonanza en que, en el marco del estilo de desarrollo prevaleciente en la región, los países gozaban de relativo equilibrio financiero interno y externo de sus economías, lo cual ofrecía la holgura suficiente como para tomar los riesgos implícitos en suscribir acuerdos cuyas consecuencias precisas no se podían medir.

En segundo lugar, hacia el interior de la región, existía un grado relativamente alto de homogeneidad entre los gobiernos, tanto en lo que respecta a sus estructuras y a sus políticas económicas, como a sus estructuras políticas. La excepción a este último punto podría ser Costa Rica, lo cual explica en alto grado la adhesión tardía de ese país al Tratado General ${ }^{3}$. En todo caso, no existían importantes diferendos políticos entre los gobiernos de la región, marcando una excepción a la larga y a veces tumultuosa historia de Centroamérica.

En tercer lugar, el marco conceptual que al menos estaba implícito en eI diseño del proceso de integración centroamericana, muy influido en materia de economía internacional por los escritos de

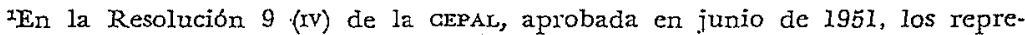
sentantes de los paises centroamericanos le pidieron a la Secretaría de la cepas que apoyara las labores de un Comité de Cooperación Económica integrado por Ios Ministros de Economía del área.

*No ha concebido la integración (en Centroamérica) en un sentido limitado, enfocado sobre todo hacia la integración en el campo industrial". CEPAL, La integración económica de Centroamérica: Su evolución y perspectivas (E/CN.12) CEE/33Rev.2) 1956, p. 6.

${ }^{{ }^{5} \mathrm{El}}$ Tratado General se suscribió por representantes de los Gobiernos de Guatemala, EI Salvador, Honduras y Nicaragua, el 13 de diciembre de 1960. Costa Rica adhirió al mismo el 23 de julio de 1962. 
la época sobre uniones aduaneras ${ }^{4}$, y en materia de relaciones internacionales por la escuela neofuncionalista ${ }^{5}$, se concibió en forma de compromisos integradores que evolucionarian en forma gradual y progresiva -algunos dirían lineal- hacia hacia formas cada vez más perfeccionadas, hasta culminar en una meta final. Así se pensaba que el Mercado Comín era un primer paso hacia la constitución de una economía de dimensión regional, mediante la cual una etapa indefectiblemente seguía a otra -Mercado Común, Unión Aduanera, Unión Económica- en el camino hacia la construcción de una unidad mayor ${ }^{6}$. En ese camino se suponfa que los gobiernos confiarian cada vez mayores facultades a las instituciones regionales, y conforme se avanzaba en las etapas previstas se ampliaría el alcance y la profundidad del proceso, por causa del desbordamiento de las acciones sometidas a tratamiento común hacia nuevos sectores o por la profundización de las mismas en determinado sector.

Finalmente, la idea de integración tuvo un reducido pero influyente grupo de patrocinadores -básicamente tecnócratas, apoyados por algunos académicos y empresarios industriales- que pudo traducir buenos propósitos en realidades al lograr una influencia decisiva entre los gobiernos, y que logró forjar un ambiente de mística en el esfuerzo cooperativo que en mucho contribuyó a los logros de los años iniciales.

Los logros fueron muchos y fecundos, si se miden a través de por la menos dos indicadores: la diversificación y modernización que significó para todas las economías el ascendente grado de industrialización, viabilizado, al menos en parte, por el mercado ampliado y la política moderadamente proteccionista que formaron parte inherente de las políticas integradoras; y el creciente grado de interdependencia económica que revelan las corrientes del comercio intrarregional. (Véase el Guadro 2). Como se podrá observar, desde 1966, el comercio intracentroamericano ha representado, en todos los años, entre la cuarta y la quinta parte de las exportaciones totales de los cinco países ${ }^{7}$. Asimismo, se establecieron instituciones comunes, algunas de las cuales, como el Banco Centroamericano de Integración Económica, tuvieron un impacto significativo sobre el desarrollo de la región.

Véase, por ejemplo, James E. Meade, The Theory of Customs Union, Amsterdam, North Holland Publishing C., 1955; y Jacob Viner, The Customs Union Issue, Nueva York, The Carnegie Endowment for International Peace, 1950.

${ }^{5}$ Ernest B. Hass, Beyond the Nation State: Functionalis and International organization, Palo Alto, Stanford University Press, 1964.

${ }^{6}$ Bela Balassa, The Theory of Economic Integration, Homewood, Mllinois, $\mathrm{Ri}$ chard D. Irwin, Inc., 1961.

Incluso la caída de esa participación relativa en el período 1976-1977 no se debió a una pérdida de dinamismo en el comercio intrarregional, sino a los excepcionales precios que rigieron en el mercado internacional para el café, lo cual elevó la participación relativa de las exportaciones extrarregionales. 
Gert Rosenthal / Algunas lecciones de la integración económica...

Guadro 2

CENTROAMERICA: ALGUNOS INDICADORES ECONOMICOS

(Millones de pesos centroamericanos)

\begin{tabular}{|c|c|c|c|c|c|c|c|}
\hline & & Exportacion & & Im & ortaciones (c & & \\
\hline . & Total & $\begin{array}{l}\text { Intrarre- } \\
\text { gional }\end{array}$ & $\begin{array}{l}\text { Porcen- } \\
\text { tajes }\end{array}$ & Total & $\begin{array}{c}\text { Intrarre- } \\
\text { gional }\end{array}$ & $\begin{array}{l}\text { Porcen- } \\
\text { tajes }\end{array}$ & $\begin{array}{l}\text { Coeficien- } \\
\text { te de } \\
\text { industria- } \\
\text { lización }\end{array}$ \\
\hline 1960 & 440,1 & 80,8 & 6,9 & 514,1 & 30,8 & 5,9 & 12,8 \\
\hline 1961 & . $\quad 454,1$ & 36,2 & 8,0 & 495,8 & 36,2 & 7,8 & 12,5 \\
\hline 1962 & $.513,7$ & 44,7 & 8,7 & 552,1 & 44,7 & 8,1 & 12,6 \\
\hline 1963 & 589,1 & 68,7 & 11,7 & 652,6 & 68,7 & 10,5 & 13,1 \\
\hline 1964 & 673,4 & 105,3 & 15,6 & 770,5 & 105,5 & 13,7 & 13,4 \\
\hline 1965 & 761,3 & 132,1 & 17,4 & 889,3 & 132,5 & 14,9 & 14,1 \\
\hline 1966 & 834,3 & 170,3 & 20,4 & 937,0 & 170,8 & 18,2 & 14,5 \\
\hline 1967 & 856,5 & 205,6 & 24,0 & $1.030,4$ & 205,6 & 20,0 & 15,0 \\
\hline 1968 & 947,3 & 246,9 & 26,1 & $1.046,2$ & 246,9 & 23,0 & 15,4 \\
\hline 1969 & 971,8 & 250,1 & 25,7 & $1.065,8$ & 250,1 & 23,5 & 15,6 \\
\hline 1970 & $1.098,0$ & 286,3 & 26,1 & $1.234,0$ & 286,3 & 23,2 & 15,9 \\
\hline 1971 & $1.107,0$ & 272,7 & 24,6 & $1.304,3$ & 272,7 & 20,9 & 16,0 \\
\hline 1972 & $1.328,8$ & 304,7 & 22,9 & $1.411,9$ & 304,7 & 21,6 & 16,9 \\
\hline 1973 & $1.663,6$ & 383,3 & 23,0 & $1.845,7$ & 383,3 & 20,0 & 16,1 \\
\hline 1974 & $2.109,2$ & 532,5 & 25,2 & $2.926,2$ & 532,5 & 18,2 & 16,2 \\
\hline $1975^{\circ}$ & $2.298,7$ & 536,4 & 23,3 & $2.945,5$ & 536,4 & 18,2 & 16,1 \\
\hline 1976 & $3.007,7$ & 649,3 & 21,6 & $8.311,9$ & 649,3 & 19,8 & 16,4 \\
\hline 1977 & $4.108,7$ & 785,4 & 19,1 & $4.357,7$ & 785,4 & 18,8 & 16,8 \\
\hline 1978 & $3.855,3$ & 862,7 & 22,4 & $4.743,5$ & 962,7 & 18,2 & 17,1 \\
\hline 1979 & $4.456,0$ & 899,2 & 20,2 & $4.946,2$ & 899,2 & 18,2 & 16,8 \\
\hline 1980 & $4.897,0$ & $1.129,2$ & 23,1 & $5.502,0$ & $1.099,6$ & 20,0 & 16,9 \\
\hline 1981 & $4.380,0$ & 924,0 & 21,1 & $5.327,0$ & 973,2 & 18,8 & 16,4 \\
\hline 1982 & $3.876,0$ & 747,5 & 19,3 & $4.202,0$ & 784,3 & 18,8 & 16,2 \\
\hline
\end{tabular}

FUENTE: CEPAL, sobre la base de cifras oficiales.

Es cierto, desde luego, que el proceso no cumplió las expectativas que algunos habían cifrado en él, y que no alteró en su esencia el estilo de desarrollo prevaleciente en todos los países - hubiera sido demasiado pedir a la integración-, pero los objetivos de alcance limitado de una integración de mexcados establecidos en el Tratado General se cumplieron casi al pie de la letra en el plazo estipulado, y persisten, con importantes variantes, que se examinan en seguida, al dfa de hoy. 


\section{I I}

En el curso de los años sesenta y setenta, y no obstante los importantes cambios que han ocurrido tanto en el ámbito internacional como a nivel de los países centroamericanos, el proceso de integración se ha caracterizado por seis rasgos salientes, los cuales se describen someramente a continuación a manera de tener un punto de referencia que permita aclarar las perspectivas del proceso. En primer lugar, ese proceso, como movimiento complementario e instrumental de los procesos de desarrollo de los cinco países de Centroamérica, tuvo que reflejar lógicamente el estilo de desarrollo que predominaba en cada uno de aquellos países. Aquel proceso respondió en su esencia a los intereses de los grupos dominantes de las sociedades centroamericanas, aunque mantuvo algunos de los rasgos reformistas que sustentaban el marco conceptual original propuesto por la GEPAL. No debe sorprender, por esa razón, que no se tuvieron lo suficientemente presentes los problemas distributivos o sociales de la región, e incluso que se facilitara la internacionalización de las economías, al adoptarse una política de puertas ab:ertas para el capital extranjero. Ello era la consecuencia lógica de un movimiento de integración ajustado a un modelo de crecimiento cuyas características son sobradamente conocidas, y que, con diferencias de grado, fue rasgo común a los cinco países. En otras palabras, siendo la integración un proceso instrumental, no cabría esperar de él que corrigiera problemas que las propias políticas nacionales no enfrentaban.

En segundo lugar, y precisamente porque la integración no era más que un reflejo de las políticas económicas acloptadas en forma más o menos homogénea a nivel de cada país, se confió en alto grado en el mecanismo del mercado para que éste asignara las actividades nuevas -o, en su caso, reasignara las existentes- a la luz del surgimiento de un mercado ampliado. Si bien es cierto que durante la década de 1960 perduraron algunos modestos intentos de introducir cierto grado de intencionalidad en la asignación de proyectos industriales entre países a través del llamado Régimen de Industrias Centroamericanas de Integración -otro rezago del marco conceptual cepalino--, éste tuvo una escasa aplicación. Asimismo, las acciones compensadoras del Banco Centroamericano de Integración Económica para apoyar proyectos localizados en los países más rezagados de la región resultaron insuficientes para evitar que se produjera una concentración de las actividades industriales en los países centroamericanos relativamente más desarrollados. Ello no significa que se siguiera una política de laissez faire precisamente, ya que cabe recordar que los gobiernos erigieron barreras arancelarias moderadamente proteccionistas e incentivos fiscales para alentar la industrialización, pero fuera de estos intentos de alterar los precios 
relativos de determinados bienes elaborados en la región frente a aquellos originarios en el mercado internacional, algunos gobiernos así como los gremios del sector privado industrial resistieron la adopción de medidas que hubieran podido, a juicio de algunos, influir directamente en la asignación de actividades respondiendo, entre otros, a criterios de una equitativa distribución geográfica de las nuevas actividades impulsadas por el Mercado Común.

En tercer lugar, durante todo el período de vigencia del Tratado General, y hasta el presente, los gobiemos demostraron una elevada dosis de pragmatismo y flexibilidad en la aplicación de las disposiciones referentes al Mercado Común. Si bien el Tratado General y los demás convenios regionales contemplaban reglas cuya aplicación a la postre resultó bastante engorrosa -muchas decisiones requería de sanción legislativa, con las consiguientes demoras que se contaban en años, y no meses- y ni siquiera contienen cláusulas de salvaguardia, los gobiemos paradójicamente encontraban soluciones a estas rigideces a través de "violaciones concertadas" de los compromisos adoptados, cuando las circunstancias así lo aconșejaban. (En algunos casos, esas violaciones incluso se adoptaron sin que se concertaran). Por otro lado, el proceso ha demostrado una sorprendente capacidad de adaptación, aún a las circunstancias más adversas, como se verá más adelante.

En cuarto lugar, y quizás debido a la relativa homogeneidad que existía entre los gobiernos de la región, resultó posible aislar, por Io menos parcialmente, la evolución que experimentaba la integración económica de los fenómenos que convencionalmente correspondían al campo de la política exterior de cada país. O sea, se logró separar el ámbito económico del ámbito polf́tico. Ast, por ejemplo, se confió la orientación de la marcha del Mercado Común a los Ministros de Economía, que se reunfan para esos efectos en los foros establecidos por el Tratado General, mientras que los Ministros de Relaciones Exteriores lo hacían dentro del marco de la Organización de Estados Centroamericanos (ODECA). De otra parte, los años sesenta -al menos hasta 1967 o 1968- estuvieron virtualmente exentos de diferendos entre los gobiernos de la región. Aun cuando surgieron las primeras diferencias importantes entre los Gobiernos de El Salvador y Honduras en torno al tema de migracionès masivas, éstas se lograron aislar del ámbito de la cooperación económica.

En quinto lugar, había existido una relación simbiótica entre el "crecimiento hacia adentro" postulado por la integración económica y la industrialización que ésta viabilizó, y el "crecimiento hacia afuera" que representa la pauta tradicional de desarrollo de los cinco países de la región. La integración, en efecto, nunca se concibió como una forma de reducir la participación de Centroamérica en el comercio internacional (aunque se concibiera como una manera 
de lograr una autonomfa mayor en la evolución de dicho comercio). En la medida que crecían el intercambio comercial y el grado de industrialización, lo hacía el comercio con terceros países. El coeficiente de importación de los cinco paises de la región, frente al resto del mundo, pasó así del $15,8 \%$ en 1950 al $26,0 \%$ en 1980 . Y también, a causa del elevado grado de interdependencia económica alcanzado entre los países, se produjo una interrelación bastante precisa entre el nivel de comercio con terceros pafses y el del intercambio intrarregional. De este modo, en los perfodos de auge del sector exportador tradicional, crecía muy dinámicamente el intercambio comercial intracentroamericano $y$ en los perfodos de recesión internacional ese intercambio perdía dinamismo, aunque a menor ritmo que el comercio internacional, por lo que representaba un papel compensador de los ciclos relacionados con el sector externo. El propio Mercado Común se constituyó, por otra parte, en campo de prueba para la exportación de manufacturas dentro de la región, que, en definitiva, saldrían a competir en el mercado internacional. Se produjo, pues, en sintesis, una compleja relación recíproca entre el comercio intercentroamericano y el comercio con el resto del mundo.

En sexto y último lugar, aunque los compromisos de integración eran tanto de carácter global - acordar el libre comercio y adoptar un arancel común- como especffico- impulsar proyectos industriales en forma conjunta, como por ejemplo desarrollar una red vial, $o$ un sistema regional de telecomunicaciones-, en realidad se puso una especial atención en los relacionados con el perfeccionamiento de una zona de libre comercio y en otros compromisos amplios. Por ejemplo, se esperaba que el conjunto de acciones que cada país se comprometió a llevar a cabo para Ilegar a constituir un solo espacio económico, habría de traducirse en una reasignación de las actividades productivas existentes y en una pauta de asignación de las actividades futuras dentro de la región distinta a la que existfa, sin que ningún país pudiera imaginar totalmente por anticipado la forma en que ese fenómeno podría afectarle.

En sintesis, tanto en Ios años 1960 -ante el trasfondo de una economía internacional en continua expansión, gobiernos relativamente homogéneos en la región, un marco conceptual que pregonaba que la integración pasaría irremisiblemente por "estadios" de cada vez mayor intensidad hasta culminar en la formación de una sola unidad económica, $y$ un pequeño pero influyente grupo de personas favorables a la idea del Mercado Común-, como en los años 1970, como se señala enseguida, el proceso de integración en Centroamérica evolucionó en el marco de características constantes.

\section{IV}

A partir de 1971, el trasfondo internacional empezó a cambiar rá- 
pidamente cuando el Gobiemo de los Estados Unidos de América decidió retirar el dólar del patrón oro. El período de expánsión en el comercio internacional, ya puesto a prueba en la segunda mitad de la década anterior, definitivamente estaba ante nuevos desafíos, que afectarían seriamente el curso de la economía internacional en la cual los pafses centroamericanos se insertaban tan decisivamente. Una de Ias muchas consecuencias inmediatas de este fenómeno fac que, ante continuas restricciones de su sector externo tradicional los países de la región demostraron cada vez mayor renuencia a cumplir sus compromisos integradores en lo que se refería al régimen de libre comercio irrestricto.

De otra parte, se produjo un acontecimiento de origen interno que se tradujo en un cambio cualitativo a las condiciones imperantes en años pretéritos, como lo fue un conflicto armado entre dos naíses miembros del Mercado Común en 1969. El hecho de que la integración económica logró sobrevivir con pocas mutaciones sustantivas, es testimonio elocuente del grado de interdependencia a que ya se había ITegado entre los cinco países, pero la ruptura entre et comercio entre. El Salvador v Honduras en 1969, y el virtual retiro de Honduras de la mayoría de sus compromisos multilaterales a finales de 1970, marcaron el suspenso formal en el funcionamiento de los órganos establecidos por el Tratado General ${ }^{8}$, y el ambiente de desolación que reinaba en los círculos más próximos al proceso de integración convenció a muchos de que la única forma de rescatar el impulso de los años sesenta era a través de una reestructuración total de los compromisos integradores ${ }^{9}$

En parte como producto de los dos hechos anteriormente señalados, se empezó a cuestionar, en algunos círculos, el marco conceptual que había orientado al proceso durante los años sesenta Tras más de una década de experiencias integradoras, no sólo en Centroamérica sino también en otros procesos en América Latina y en el resto del mundo, se había constatado que contrariamente a lo postulado por los teóricos, en ninguno de dichos procesos se había producido una ampliación progresiva de los compromisos integradores o de las atribuciones que los gobiernos habían confiado a las instituciones regionales. Más bien, en la mayoría de los procesos, diff-

\footnotetext{
- ${ }^{8}$ Así, dejó de funcionar el llamado Consejo Económico Centroamericano, compuesto por los Ministros de Economía de cada uno de los pafses, y que se establece en el Tratado General como el máximo organismo del proceso. En sustitución de este foro. Ios Gobiernos acordaron establecer, primero la llamada "Comisión Normalizadora del Mercado Común Centroamericano", y después, simplemente las reuniones de los titulares de Economia. Sin embargo, el comercio recíproco entre la mayoría de los pafses - Honduras sería ta excepciónse siguió rigiendo prácticamente por las reglas establecidas en el Tratado General.

${ }^{\circ}$ Ello llevó a los Gobiernos a establecer, en 1973, un Comité de Alto Nivel para la Reestructuración del Mercado Común Centroamericanó.
} 
cilmente se habian cumplido las metas preestablecidas - ello fue el caso, por ejemplo de la ALALC- y en los ejercicios más exitosos, como el centroamericano, los procesos habían encontrado una especie de "punto de equilibrio" en el que tendían a estancarse ${ }^{10}$. En el caso concreto de Centroamérica, la "crisis" de la integración no se refería tanto a la brecha entre propósitos y realizaciones, sino a la brecha entre realizaciones y expectativas: no se avanzó hacia la unión aduanera, ni menos hacia la unión económica. En otras paIabras, más que una crisis real, la integración en Centroamérica se enfrentó a una crisis de expectativas.

Fue así como se hizo cada vez más popular en América Latina un enfoque más pragmático de la integración, que algunos llamaban la "integración informal" o la "integración por proyectos", que a veces abandonaban los enfoques totalizadores y las metas finales, sustituyéndolas por -o complementándolas con- acciones conjuntas en aquellas áreas de quehacer económico que admitfan cooperación entre dos o más países. Este enfoque sin duda influyó mucho en la concepción tanto del Sistema Económico Latinoamericano (SELA), así como en el segundo Tratado de Montevideo, que estableció la Asociación Latinoamericana de Integración (ALADI). Y, si bien estas ideas aún no habían sido aceptadas en el caso de Centroamérica, ya eran objeto de intenso debate.

En sintesis, en la década de los años setenta, contrariamente a la experiencia del decenio anterior, surgieron dudas sobre las orientaciones generales de la integración centroamericana. Ello condujo a dos consecuencias contradictorias: por un lado, dio lugar a un intenso debate sobre la naturaleza de la "reestructuración del proceso", que a la vez contribuyó a un empantanamiento de acciones concretas potenciales para sacar a la integración del "punto de equilibrio" en que se encontraba; por otro, contribuyó al abandono de reglas fijas derivadas del ordenamiento juridico vigente - pero puesto en suspenso por la acción unilateral de Honduras adoptada a finales de 1970- y facilitó un creciente pragmatismo con el fin de mantener vigentes los niveles de interdependencia económica establecidos en años pretéritos. Así, no obstante que el nivel de intercambio comercial creció a ritmos menores que en la década anterior ${ }^{11}$, continuó creciendo. mientras que el proceso seguía dando señales de cierta vitalidad. Nuevamente, se hacía patente la persistencia de los centroamericanos de proteger el esfuerzo cooperativo construido en los años pretéritos.

\footnotetext{
${ }^{10}$ Téase, CEPAl. Centroamćrica: Evolución Económica desde la Postgucrra. (CEPAL/MÉx/ODr/34Rcv.1). enero de 1980. Capitulo IIr.

mDurante el perfodo 1960-1968, el intercambio comercial creció a tasas acumulativas anuales cercanas al $30 \%$, tanto en valores corrientes como constantes, mientras que durante el período 1969-1978, el ritmo de crecimiento del inter-
} 
Con todo, y como resultado de los fenómenos antes descritos, se erosionó la base de confianza mutua y de mística integradora que habían contribuido a darle al proceso su impulso inicial en los años sesenta. Esta se sustituyó por una gradual burocratización de algunas de las instituciones que tenían a su cargo impulsar la integración, de un creciente escepticismo entre distintos estratos de la población sobre las perspectivas del proceso, y de un franco cuestionamiento, en algunos círculos, de sus beneficios potenciales.

Durante un breve período, incluso se presentó la posibilidad de que los acontecimientos en el ámbito político se desbordaran hacia el ámbito económico, poniendo fin a la separación exitosa de posib'les diferencias políticas entre gobiernos, por un lado, $y$ el funcionamiento del Mercado Común, por el otro. El origen de esta situación fue, desde luego, el conflicto armado entre EI Salvador y Honduras. Ese conflicto si fue capaz de interrumpir las relaciones económicas entre los dos pafses -situación que perduró hasta 1981 cuando se reanudo, sobre una base incipiente, el comercio bilateral-, que tenfan una larga tradición de interdependencia que incluso antecedió los arreglos formales de los años cincuenta. Sin embargo, como ya quedó señalado, el conflicto no fue capaz de interferix con los arreglos multilaterales entre esos dos países y los otros tres miembros del Mercado Común, e incluso se mantuvo un modesto comercio indirecto entre las dos partes afectadas, a través de terceros países. Así, en la práctica, un grave conflicto politico no fue capaz de alterar, en forma contundente, el funcionamiento del Mercado Común más o menos en los términos previstos en el Tratado General.

\section{$\mathrm{V}$}

Nuevamente, hacia finales de los años setenta se produjeron importantes acontecimientos que habrian de influir decidamente sobre el curso de la integración centroamericana, y que están alterando las caracterfsticas básicas del proceso antes descritas. Entre éstos, se destacan dos: el rápido deterioro de la economía internacional, como producto de las políticas de estabilización y de austeridad aplicadas en varios países industriales, y especialmente en los Estados Unidos de América, y la creciente heterogeneidad de los gobiernos de la región, con el surgimiento de un régimen nacido de una insurrección popular en Nicaragua.

En lo que se refiere al primer aspecto, ya desde 1979 se vieron enfrentados los países de la región a serios problemas en su comercio exterior derivados de la reducción de la demanda externa expe-

cambio comercial alcanzó el $15 \%$ en valores corrientes y aproximadamente el $6 \%$ en valores constantes. 
rimentada por la mayoría de los productos que exporta Centroamérica, y al deterioro de la relación de precios del intercambio, sobre todo en 1979, en buena parte por un nuevo e importante aumento en los precios de los combustibles líquidos que la región importa. A estas circunstancias de signo negativo se sumó el comportamiento errático de las cuentas de capital, que revelaron una cuantiosa fuga, alentada por los factores de orden extraeconómico que se presentaron en 'Centroamérica, y la dificultad creciente de movilizar financiamiento externo para una región que la comunidad financiera internacional percibía como cada vez más riesgosa. Por añadidura, las altas tasas de interés imperantes en los mercados financieros vinieron a elevar la carga que representaba la deuda externa ya desembolsada. El panorama revela un progresivo deterioro en los años subsiguientes; así, para la región en su conjunto, el producto interno bruto en 1979 creció en un 3,6\% en términos reales; esa tasa fue del $1,0 \%$ en 1980; cayó en $1,0 \%$ en 1981 , y en $3,0 \%$ en 1982. El grado del desplome fue de tal magnitud que al presente el ingreso real por habitante en Costa Rica, Guatemala y Honduras, apenas equivale al nivel registrado en 1976, mientras que en el caso de El Salvador y Nicaragua, éste se retrotrae a las cifras alcanzadas durante la primera mitad de los años sesenta ${ }^{12}$.

El segundo aspecto tiene implicaciones múltiples. No se trata únicamente de la existencia en la región de diversos gobiernos que persiguen objetivos de política económica disímiles, emprendiendo distintos caminos para alcanzarlos, sino que han surgido importantes diferendos en el ámbito político que amenazan con desbordarse hacia el quehacer de la cooperación económica. De otra parte, los intensos conflictos que existen en otros países de la región, especialmente en EI Salvador, y la destacada presencia de diversos actores internacionales en la región que le han introducido a dichos conflictos una dimensión Este-Oeste, han exacerbado notablemente las diferencias entre los gobiernos de la subregión. De ello. la prensa internacional ha dado amplio testimonio en los últimos meses.

Estos dos fenómenos nuevos, o al menos de intensidad cualitativamente distinta que en años pretéritos, podrían cambiar la fisonomía de la integración, e incluso -aunque no sea probable- interxumpir el grado de interdependencia económica alcanzada entre los cinco paises a lo largo de los últimos veinte años.

Ya quedó señalado en páginas anteriores que históricamente ha existido una relación simbiótica entre el "crecimiento hacia adentro" que facilitó la integración a través de la industrialización, y el "crecimiento hacia afuera" vinculado con la inserción tradicional de Centroamérica a la economía internacional. En la coyuntura de

I"CEPAL, La crisis en Centroamérica: origenes, alcances $y$ consecuencias (E/CEPAL /G.I261), 22 de septiembre de 1983. 
Ios últimos tres años, además de la progresiva contracción de la demanda global experimentada por los países, casi todos se han visto en la necesidad de restringir sus importaciones globales, a veces incluyendo aquellas provenientes del resto de la región. De otra parte, la escasez de divisas ha sido tal en algunos países, que sus respectivos bancos centrales no han podido hacer efectivo sus saldos deudores en el comercio intrarregional a través de la Gámara de Gompensación Centroamericana.

Nada de lo anterior tendría necesariamente por qué reducir el grado de interdependencia económica entre los países de la región. Al contrario, las acciones colectivas podrfan contribuir a atenuar los efectos depresivos originarios en el sector externo tradicional. $y$ el intercambio comercial intracentroamericano podría volver a jugar un papel compensador de los efectos cíclicos del comercio con terceros países que han jugado en el pasado.

Para hacerle frente a esta situación, en efecto, los países acudieron a mecanismos bilaterales y multilaterales, haciendo patente una vez más su vocación histórica de mantener vigente la interdependencia, como reconocimiento del papel que le corresponde desempeñar a la integración en el desarrollo de las cinco economías. En lo que se refiere a los primeros, los bancos centrales de los países superavitarios en el comercio intrarregional extendieron líneas de crédito a los países deficitarios por más de 300 millones de dólares durante el período 1980-1982. Al presente, (noviembre de 1983), alrededor de 250 millones de dólares de esos créditos están pendientes de pago, con lo cual la capacidad de los bancos centrales acreedores de continuar extendiendo financiamiento llegó próximo a su punto de agotamiento. Con todo, llama la atención la magnitud de los créditos envueltos entre bancos centrales de países que, en el ámbito político, tienen importantes diferencias. En cuanto a lo segundo, en 1981 los cinco gobiernos de la región establecieron un mecanismo multilateral -el "Fondo Centroamericano del Mercado Común"- para financiar los saldos deudores resultantes de las liquidaciones periódicas que la Cámara de Compensación Centroamericana practica. Asimismo, los cinco países realizaron gestiones conjuntas frente a la comunidad financiera internacional en búsqueda de recursos para capitalizar dicho Fondols. Esas gestiones resultaron relativamente infructuosas hasta la fecha.

En síntesis, durante el período 1980-1982 los propios gobiernos de la región hicieron un considerable esfuerzo para mantener vigentes los niveles de intercambio comercial, a manera de que dicho in-

${ }^{13}$ Ese es el propósito del foro organizado por el Banco Interamericano de Desarrollo, el cual convocó a la primera Reunión Especial del Programa para el Desarrollo Económico del Istmo Centroamericano, la que tuvo Iugar en Bruselas, Bélgica, del 13 al 15 de septiembre de 1983 . 
tercambio continuara cumpliendo su papel tradicional de compensar las tendencias adversas del comercio con terceros pafses. Sin embargo, ya en 1981 ese comercio perdió dinamismo, sin duda como resultado de los problemas globales de balance de pagos que la mayoría de los países enfrentaban, y en 1982 esa tendencia se agravó. (Véase de nuevo el Cuadro 2). Si bien hasta 1982 la contracción en el comercio intrarregional no fue significativameste mayor a la contracción global del comercio, desde luego no existe garantía alguna que esa situación se podrá mantener en 1983. Ello no significa que el intercambio comercial cesará, pero sí que su evolución estará condicionada a la capacidad de importar que cada país genere a través de sus propias exportaciones al resto de la región. En otras palabras, el límite al intercambio comercial podría establecerse en los próximos años por la disponibilidad de divisas de parte de los países deficitarios en el comercio intrarregional para cubrir esos saldos en monedas fácilmente convertibles.

Lo anterior lleva implícito que una de las características centrales del proceso de integración en el pasado podría cambiar de signo en los próximos años, ya que el comercio intrarregional, lejos de compensar la baja que los países podrían experimentar en su relav cionamiento con el resto del mundo, podría ahora verse adversímente afectado por la severa crisis del sector externo que la mayoría de los países afrontan, sumándose así a los fenómenos que han dado Iugar al panorama recesivo generalizaro en la región.

En lo que se refiere al creciente grado de heterogeneidad presente en la región, este fenómeno también podría anunciar un importante cambio en las características del proceso, tal y como funcionaba en el pasado, tanto por consideraciones de tipo económico como extraeconómico.

En lo que se refiere a lo último, la heterogeneidad aludida ha contribuido a las diferencias políticas que existen en la región. Esas diferencias hản sido fuertemente exacerbadas por el papel que han jugado diversos actores externos y han captado la atención mundial en los últimos meses. Ello $p^{T}$ antea la duda si será posible en el futuro, como sí lo fue en el pasado $-\mathrm{y}$ ello, se insiste, fue una de las características centrales del proceso- separar la integración económica de los fenómenos que correspondían convencionalmente al campo tradicional de la política exterior. No es secreto, por ejemplo, que se han producido enfrentamientos armados en la frontera entre Nicaragua y Honduras, y que han surgido profundas diferencias entre El Salvador y Nicaragua, por un lado, y Costa Rica y Nicaragua, por el otro.

Hasta la fecha, y no obstante estas tensiones, los gobiernos han demostrado su capacidad de continuar cooperando en el ámbito económico. Así, a pesar de que se ha erosionado aún más el ambiente de confianza mutua y de credibilidad en el proceso, el nivel 
de intercambio se mantiene, los gobiernos actúan conjuntámente para superar algunos problemas comunes -el financiamiento del comercio intrarregional, por ejemplo- $y$ se siguen llevando a cabo reuniones entre Ministros de Economía, presidentes de Bancos Centrales, e incluso de Cancilleres, en torno a la iniciativa de distensión política impulsada en la región por Ios Gobiernos de Colombia, México; Panamá y Venezuela. Es de suponer, sin embargo, que la capacidad de separar el ámbito de la cooperación económica de las tensiones políticas tiene un límite, y que la región está mucho más cerca de ese límite hoy que en cualquier momento desde que se suscribió el Tratado General.

¿Guál es el límite? Resulta imposible precisarlo de antemano. Sin duda, una agresión armada contra un país - ya una hipótesis extrema, pero no del todo descartable- que en el contexto actual tendería rápidamente a internacionalizarse, daría término a este experimento de cooperación multilateral entre cinco paises. Una continuada polarización de posiciones entre países podría tener el mismo efecto. En todo caso, a los considerables costos polfticos y sociales de un desbordamiento de cualquier diferendo entre gobiernos habría que añadir el costo económico que significaría prescindir de los beneficios que la integración ha deparado para los pafses, con diferencias de grado entre uno y otro. De otra parte, el elevado grado de interdependencia económica ya alcanzado ha demostrado ser, hasta ahora, suficiente impedimento para que las diferencias polf́ticas se desborden al quehacer económico ${ }^{14}$. En ese sentido, la cooperación intracentroamericana eventualmente podría contribuir a una distensión en la arena política, no sólo por las necesidades objetivas que la interdependencia económica plantea a cada uno de los países, sino porque, al aprender a cooperar en el terreno económico, gobiernos heterogéneos quizás también aprenden a convivir.

Pero la creciènte heterogeneidad de gobiernos también tiene otra implicación sobre el estilo de la integración que se impulse en adelante. Como ya quedó señalado, el proceso de integración debe percibirse como un instrumento de desarrollo, complementario a Ios esfuerzos que se llevan a cabo en cada pass. En la medida en que Ios objetivos de desarrollo de los cinco países eran más o menos homogéneos, no fue diffcil concebir un proceso de integración que reflejara el estilo de desarrollo que predominaba en cada uno de los pałses. Sin embargo, en la Centroamérica contemporánea, con-

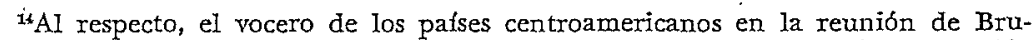
selas citada en la nota anterior, señaló: "El imperio de la necesidad también nos enseñó a separar la empresa económica de la política. A tal grado, que ni las diferencias ideológicas ni la diversidad de sistemas han sido capaces de detener el desenvolvimiento de la integración. Aún el conflicto armado entre dos paises en 1969 no causó daño irreparable al esquema multilateral". 
viven gobiernos con objetivos de política económica disímiles, sobre todo en torno a temas como el grado de importancia que se atribuye a las políticas distributivas, el papel que corresponde al sector público en la economía, el grado de intencionalidad en la aplicación de la política económica, el papel de la movilización popular y las caracteristicas de relacionamiento externo de las economfas. Ello no significa de ninguna manera que la heterogeneidad en. la aplicación de políticas económicas haga inviable un proceso de integración, puesto que persiste suficiente comunidad de intereses entre todos los países como para que la integración responda a algunos objetivos de todos Ios gobiernos. Lo que sí significa es que de aquí en adelante habrá de concebirse la integración sobre bases distintas que en el pasado. En otras palabras, por si todavía cabía alguna duda en los años setenta, en el presente queda abundantemente claro que habrá de renunciarse a la pretensión de intentar conciliar las políticas económicas de todos los países en todas y cada una de sus partes, con miras a llegar, sobre una base gradual y progresiva, a formar una sola economía de dimensión regional. Lo que cabría, más bien, sería identificar puntos de coincidencia entre economías cuyos objetivos de politica económica pueden ser distintos, pero que admiten esfuerzos conjuntos para apoyar el logro de esos objetivos.

\section{VI}

En un ambiente de gran tensión política y social en algunos pafses $y$ de serios conflictos entre gobiernos, el espectador lejano podria concluir que el proceso de integración centroamericana ha perdido toda relevancia. Ciertamente, las tensiones antes descritas han alterado las relaciones de los gobiernos - la sobrevivencia Iógicamente se antepone al desarrollo económico- y la plataforma mínima de confianza mutua que se requiere para la buena marcha de un proceso integrador se está erosionando cada vez más. Con todo, el grado de interdependencia económica a que se había llegado en la región hacia finales de los años setenta ha sido de tal magnitud que el proceso de integración continúa reflejando una vitalidad nada despreciable. Alrededor del 20\% de las exportaciones totales de los cinco países se comercia entre ellos; la suerte del sector manufacturero en cada país depende en alto grado del funcionamiento del régimen de intercambio comercial, y los gobiernos continúan revelando cierta vocación para emprender algunas acciones en forma mancomunada en campos tan diversos como la energía, los transportes, el comercio exterior y el financiamiento externo ${ }^{15}$.

${ }^{18}$ Por ejemplo, sólo en el segundo semestre de 1983, y no obstante las crecientes tensiones entre diversos paises en el ámbito polftico y militar, Ios Ministros o Encargados del Sector de la Energla se reunieron para adoptar un pro- 
El principal problema que enfrenta la región hoy se refiere sin duda a encontrar una salida a las graves tensiones-sociales y politicas que confrontan varios países a nivel interno, y Centroamérica como un todo en sus relaciones intrarregionales. Ante el grado de polarización alcanzado y la presencia de actores externos activos con intereses antagónicos, ello no sexá fácil y es previsible que el tema del desarrollo económico continuará relegado a un segundo plano de importancia durante algún tiempo. La manifestación concreta de este estado de cosas sobre la cooperación económica en el ámbito regional es el peligro latente de que Ios conflictos de carácter político se desborden al quehacer económico, y que se trunque el grado de interdependencia ya alcanzado. Sin embargo, las experiencias de los últimos años confirman una vez más la tenacidad con que los gobiernos mantienen esos lazos de interdependencia, ast como lá capacidad de la integración de adaptarse a nuevas circunstancias, por lo que cabe pensar que la cooperación económica no sólo perdurará, sino que incluso puede jugar un papel en la búsqueda de una distensión a nivel de cada uno de los países y de las relaciones intrarregionales.

De lograrse lo anterior, es previsible que Centroamérica seguirá siendo una región con gobiernos y sistemas políticos heterogéneos, pero no por ello sin una fuerte comunidad de intereses. El hecho de que convivan gobiernos con objetivos e instrumentos disimiles en materia de política económica, de ninguna manera significa que no haya un espacio para continuar impulsando la cooperación intrarregional, sino únicamente significa que habrá que cambiar el enfoque de esa cooperación en los años ochenta y más allá. Ya no cabe, por ejemplo, pensar en una gradual y progresiva coordinación de todas las políticas económicas de los cinco Estados a manera de llegar a formar una sola unidad económica de dimensión regional, puesto que ello claramente plantearía conflictos irreconciliables entre la conducción de la política económica en cada país y la conducción de una supuesta política económica regional. Pero ello no impide que los cinco pafses lleven a cabo actividades conjuntas en materia económica.

grama de Desarrollo Energético Centroamericano; los Ministros de Transportes se reunieron para consolidar la red vial centroamericana y para acordar medidas concretas destinadas a facilitar el transporte intrarregional; continuaron desarrollándose los proyectos de interconexión eléctrica, mediante los cuales incluso Honduras y Nicaragua intercambian energfa; se llevó a cabo lá Reunión Especial del Programa para el Desarrollo Económico del Istmo Centroamericano ya aludido; se logró elegir, por unanimidad, al nuevo Presidente del Banco Centroamericano de Integración Económica; se celebraron dos reuniones de las líneas aéreas de los cinco páses de la región a manera de impulsar la cooperaçión reciproca, y continuaron efectuándose con relativa normalidad las reuniones de los Ministros de Economía, de Ios Viceministros de Integración y de los Presidentes de los Bancos Centrales. 
Dicho en otra forma, el hecho de que se reconociera taxativamente el carácter complementario e instrumental del movimiento de integración lieva implícito la renuncia a la pretensión de intentar conciliar las políticas económicas de todos los países, en todos y en cada una de sus partes. Por el contrario, habría que identificar puntos de coincidencia entre economfas cuyos objetivos de política fuesen distintos - reconociendo que algunos problemas que afrontan son comunes- para llevar a cabo esfuerzos conjuntos de valor intrínseco para todas las partes. Abundan ejemplos de acciones que no por fuerza exigen compromisos globales de coordinación, entre los cuales se destaca el comercio recíproco bajo un régimen preferencial. Asimismo, los países podrían seguir impulsando proyectos regionales industriales y agrícolas; pueden cooperar en materia energética - por ejemplo, a través de la interconexión de sus sistemas de distribución-; pueden desarrollar parte de su infraestructura y los servicios de transporte en forma coordinada, y pueden cooperar para mejorar su inserción en la economía internacional. Nada de lo. anterior exige compromisos que obliguen subordinar los objetivos nacionales a un compromiso abstracto de carácter regional, pero sí le otorga a la integración el papel funcional que se le supone en apoyo a los esfuerzos que cada uno de los países desplegaría para impulsar su propio desarrollo, en el marco de sus propios objetivos. Un enfoque de esta índole también facilitaria ampliar el ámbito geográfico de la cooperación, para incorporar, por ejemplo, a Panamá, e incluso a otros países latinoamericanos.

Un estilo de integración que tenga objetivos de alcance limitado habrá de requerir un elevado grado de flexibilidad en la aplicación de Ios compromisos integradores, e instancias negociadoras que permitan a los países cotejar permanentemente los objetivos de la poIftica económica que les sean propios con las posibilidades concretas que les vaya ofreciendo la cooperación intrarregional, precisamente para alcanzarlas. Exigirá asimismo instituciones regionales donde puedan identificarse los proyectos y programas susceptibles de cooperación y su realización pueda promoverse. Todo ello está al aIcance no sólo de los países centroamericanos, sino de las otras agrupaciones subregionales que persisten en América Latina, y por ello no corresponde abandonar los esfuerzos por mantener vigente la interdependencia económica alcanzada, así como procurar un mayor aprovechamiento de las potencialidades que esos esfuerzos entrañan. 